\title{
Kinetics of Gentamicin Uptake and Release in the Rat Comparison of Inner Ear Tissues and Fluids with Other Organs
}

Patrice Tran Ba Huy* $¥$, Philippe Bernard\$, and Jochen Schacht*

${ }^{*}$ Biochemistry Laboratory, Kresge Hearing Research Institute, Ann Arbor, Michigan, 48109; ¥Chaire de Clinique d'Oto-Rhino-

Laryngologie Hôpital Lariboisière and Institut National de la Santé et de la Recherche Medicale Unit 251, Faculté X. Bichat, Université Paris 7, France; §Department of Otorhinolaryngology, Children's Hospital of Eastern Ontario, Ottawa, Canada

\section{Abstract}

The kinetics of entry and release of gentamicin was investigated in fluids and tissues of the inner ear of the rat, as well as in renal cortex, and in organs that do not share susceptibility to the toxic effects of aminoglycosides. Various modes of administration were used to achieve different patterns of drug plasma concentrations. Electrophysiological and histological examinations were performed to correlate pharmacokinetics and ototoxicity.

Results show that: (a) the uptake of the drug by the inner ear tissues is dose dependent and manifests a rapid saturation kinetics with a concentration plateau of about $1 \mu \mathrm{g} / \mathrm{mg}$ of protein. (b) The low ratio of the perilymph and endolymph to plasma concentrations argues against the concept of an accumulation of the drug in the inner ear over drug levels in plasma, which has been considered as the basic mechanism of ototoxicity. (c) In renal cortex, the kinetics appears similar to that of the inner ear but the concentrations achieved are 10-fold higher than in cochlear tissues. (d) In other organs (liver, heart, lung, and spleen), no saturation could be demonstrated within the duration of the experiment. (e) Ototoxicity seems to be related to the penetration of the drug into compartment(s) from which the half-life of disappearance is extremely slow. $(f)$ Rapid uptake, early saturation, and long exposure of the tissues to the drug may account for the development of toxicity in inner ear and kidney.

\section{Introduction}

Since the early works of Voldrich (1), Vrabec (2), and Stupp (3) it has been speculated that the pathogenesis of aminoglycoside ototoxicity is related to the accumulation of the drug in the inner ear fluids; the more ototoxic the aminoglycoside, the longer its retention in the labyrinthine fluids. Subsequent studies (412) apparently supported this theory. We were, however, unable to demonstrate such a phenomenon of accumulation over plasma values in the fluids of the inner ear. In rats receiving a 6-d constant infusion of $15 \mu \mathrm{g} / \mathrm{min}$ of gentamicin, the ratio of perilymph to plasma levels remained low for the duration of the experiment, regardless of the drug levels in plasma, which were increasing due to the progressive decline of the glomerular filtration rate; concomitantly, the endolymphatic drug concentra-

The majority of this work was performed in the Biochemistry Laboratory of the Kresge Hearing Research Institute.

Address reprint requests to Dr. Tran Ba Huy, Département de Physiologie, Faculté X. Bichat, 16 rue Henri Huchard, 75018 Paris, France. 1986.

Received for publication 22 April 1985 and in revised form 17 January

J. Clin. Invest.

(C) The American Society for Clinical Investigation, Inc.

$0021-9738 / 86 / 05 / 1492 / 09 \$ 1.00$

Volume 77, May 1986, 1492-1500 tions remained at a steady low value and at a rather constant ratio to the concentrations in perilymph $(13,14)$. Similarly, levels of the antibiotic in lateral wall and organ of Corti of guinea-pigs that received chronic parenteral administration of neomycin for up to $3 \mathrm{wk}$ were not higher than levels in nonsusceptible body organs (15). However, because of the diversity of experimental conditions, the issue of the accumulation phenomenon remained debatable.

We, therefore, designed the present study to investigate the kinetics of entry and release of gentamicin in both the fluids and the tissues of the inner ear of the rat during various modes of administration. The kinetics of the drug were assessed in the renal cortex, a structure already extensively investigated (1621), simultaneously with organs that do not share susceptibility to the toxic effects of aminoglycosides. Animals were also subjected to electrophysiological and histological examinations in an attempt to correlate pharmacokinetics and ototoxicity.

Results show that: $(a)$ the uptake of gentamicin by the tissues of the inner ear is dose dependent, manifests rapid saturation kinetics, and leads to a distribution of the drug into different compartments; (b) no accumulation develops either in tissues or in labyrinthine fluids; $(c)$ ototoxicity seems to be related to the penetration of the drug into compartment(s) from which the half-life of disappearance is extremely slow; $(d)$ rapid uptake, early saturation, and long exposure of the tissues to the drug may account for the development of toxicity in inner ear and kidney.

\section{Methods}

\section{Gentamicin administration}

The uptake of gentamicin was studied in 228 male Sprague-Dawley rats, weighing $200-250 \mathrm{~g}$. The drug was administered by single intramuscular injection (group I) of $10 \mathrm{mg} / \mathrm{kg}$ (subgroup Ia, $n=20$ ) or $100 \mathrm{mg} / \mathrm{kg}$ body weight (subgroup Ib, $n=20$ ); and by constant infusion (group II) at four different rates: $1.5 \mu \mathrm{g} / \mathrm{min}$ (subgroup Ila, $n=37$ ), $4.5 \mu \mathrm{g} / \mathrm{min}$ (subgroup IIb, $n=27$ ), $15 \mu \mathrm{g} / \mathrm{min}$ (subgroup IIc, $n=27$ ), and $150 \mu \mathrm{g} / \mathrm{min}$ (subgroup IId, $n=23$ ). For infusions of up to $12 \mathrm{~h}$, the drug was delivered in 0.15 $\mathrm{M} \mathrm{NaCl}$ via a jugular venous catheter at a constant rate of $60 \mu \mathrm{l}$ infusate/ min and different rates of gentamicin delivery were obtained by varying the concentration of the drug in the infusate. For long-term (up to 24d) infusions, two osmotic minipumps (Alset; Alza Corp., Palo Alto, CA) were implanted subcutaneously under brief ether anesthesia. To achieve the four different rates, each minipump delivered $1 \mu \mathrm{l} / \mathrm{h}$ (model 2001) of a 45,135 , or $450 \mathrm{mg} / \mathrm{ml}$ solution of gentamicin, or $10 \mu \mathrm{l} / \mathrm{h}$ (model $2 \mathrm{ML1}$ ) of a $450 \mathrm{mg} / \mathrm{ml}$ solution of gentamicin. In the first three subgroups, new minipumps were implanted every sixth day under brief ether anesthesia. At that time, the delivery rate of gentamicin and the renal function were evaluated by measuring gentamicin concentration and blood urea nitrogen (BUN) ${ }^{1}$ in plasma sampled from the tail. The infusion was maintained up to $24 \mathrm{~d}$ in subgroup IIa, but had to be stopped at 12,10 ,

1. Abbreviations used in this paper: BUN, blood urea nitrogen; SPL, sound pressure level. 
and $2 \mathrm{~d}$ in subgroups IIb, IIc, and IId, respectively, because of the development of severe renal failure.

The release of the drug after termination of treatment was studied for $10 \mathrm{~d}$ in the $\mathbf{4 0}$ animals of group I. In $\mathbf{7 4}$ animals (group III) release was measured for $30 \mathrm{~d}$ after two conditions of drug administration: after a 3-h constant infusion of $15 \mu \mathrm{g} / \mathrm{min}$ (subgroup IIIa, $n=34$; at the end of the infusion period, the plasma concentration of gentamicin was measured to ensure that infusion had been properly performed) or after a daily injection of $100 \mathrm{mg} / \mathrm{kg}$ i.m. for 30 consecutive days (subgroup IIIb, $n=45$ ). In this series, five animals died of renal failure during the second or the third week of the treatment period. In the $\mathbf{4 0}$ surviving animals, this regimen induced ototoxicity without a marked renal impairment and thus allowed a 30-d follow-up.

\section{Sampling procedures}

Samples of endolymph, perilymph, plasma, and various organs were obtained at various times from animals in the different subgroups. In group I, samples were taken at 3,6, and $24 \mathrm{~h}$ as well as on the 5th and 10th days. Additional plasma samples were collected at $30 \mathrm{~min}$ and $1 \mathrm{~h}$ to determine peak drug levels. In group II, depending on the infusion rates, samples were taken at times ranging from $30 \mathrm{~min}$ to $24 \mathrm{~d}$. In subgroup IIIa, they were collected at the end of the infusion period and then daily during the next $5 \mathrm{~d}$, as well as on the 10th, 15th, 20th, and 30th days. In subgroup IIIb, the first sampling was made $24 \mathrm{~h}$ after the last injection and then at the same intervals as in subgroup IIIa.

At the time of sampling, the animal was anesthetized with thiobutabarbital $(100 \mathrm{mg} / \mathrm{kg})$, tracheotomized, and maintained at $36.5^{\circ} \mathrm{C}$ on a heating pad. One endolymph sample of about $200 \mathrm{nl} /$ animal was collected from one side, as described previously (13). The purity of the sample was immediately ensured by measuring the $\mathrm{Na}$ and $\mathrm{K}$ concentrations in a 25-nl aliquot by flame emission photometry. A 125-nl aliquot of the remaining endolymph was withdrawn in a calibrated micropipette and diluted in $50 \mu \mathrm{l}$ of distilled water. The diluted sample was stored at $-30^{\circ} \mathrm{C}$. In case of failure to obtain pure endolymph, a second attempt was made on the other ear. Because we had found previously (13) that gentamicin was not detectable in endolymph for $10 \mathrm{~h}$ in rats that were given a $15 \mu \mathrm{g} / \mathrm{min}$ constant infusion, endolymph was not sampled before that time in the present study, except in subgroup IId, i.e., in rats receiving $150 \mu \mathrm{g} \mathrm{drug} / \mathrm{min}$.

One perilymph sample of about $6 \mu \mathrm{l} /$ animal was then collected from one cochlea using an external approach to the first coil of the scala vestibuli, as previously described (13). $5 \mu \mathrm{l}$ of the sample were drawn into a glass capillary tube (Microcap; Drummond Scientific Co., Broomall, PA) and diluted in $50 \mu \mathrm{l}$ of distilled water. The diluted sample was stored at $-30^{\circ} \mathrm{C}$. Perilymph, like endolymph, was not sampled before $12 \mathrm{~h}$, except in subgroup IId, for the reasons described above.

Thereafter, a blood sample of about $300 \mu \mathrm{l}$ was collected through an indwelling femoral catheter on dry lithium heparinate and the tube was centrifuged for $2 \mathrm{~min}$. A $100-\mu \mathrm{l}$ aliquot of plasma was stored at $-30^{\circ} \mathrm{C}$.

The animal was then exsanguinated through the femoral catheter and perfused with isotonic saline for $5 \mathrm{~min}$ to rinse the vascular bed. Samples of heart, liver, lung, spleen, and renal cortex were taken and homogenized with a Polytron (Brinkmann Instruments Co., Westbury, $\mathrm{NY}$ ) in $0.2 \mathrm{M}$ sodium phosphate, $\mathrm{pH} 8$. The two bullae were removed and the cochlea was rinsed thoroughly with isotonic saline through the windows. The tissues of the lateral wall, i.e., stria vascularis and spiral ligament, and of the organ of Corti were dissected from both ears and pooled separately. Tissues were collected in $0.2 \mathrm{M}$ sodium phosphate, $\mathrm{pH} 8$, and homogenized as previously described (22). Homogenates were transferred to propylene tubes in which all subsequent manipulations were performed.

The number of data points for individual tissue and conditions may not always correspond to the number of animals in that subgroup, as a few tissue samples were lost during manipulation.

\section{Electrophysiological and histological studies}

37 animals (group IV) were studied along with the above groups for electrophysiological and histological assessment of the inner ear. These animals were submitted to the same drug treatment as those subjected to the release study (group III). They were divided into four subgroups: (a) 9 rats received a 3-h constant infusion of $15 \mu \mathrm{g} / \mathrm{min}$ i.v. (subgroup IVa); (b) 11 rats were given a single dose of $100 \mathrm{mg} / \mathrm{kg}$ daily for 30 consecutive days (subgroup IVb); (c) 3 rats were given a single dose of $100 \mathrm{mg} / \mathrm{kg}$ i.m. (subgroup IVc); (d) 14 rats were given a single intramuscular dose of isotonic saline and constituted control animals (subgroup IVd). All rats had free access to food and water.

Electrophysiological study. Auditory brain stem-evoked electrical activity was recorded under light anesthesia (ketamine $\mathrm{HCl}, 30 \mathrm{mg} / \mathrm{kg}$ ) in an acoustically and electrically shielded room, every $2 \mathrm{~d}$ during the first $30 \mathrm{~d}$ after the cessation of infusion or the last injection, then every $15 \mathrm{~d}$ for the 3 consecutive months. The body temperature was kept constant using a warming waterbed. Recording electrodes (regular electroencephalogram subdermal stainless steel needles; Grass Medical Instruments Co., Quincy, MA) were located at the vertex (active), the base of the tail (reference), and the left thoracic area (ground). Electrical activity was amplified with $30-3000 \mathrm{~Hz}(-3$ decibel [dB]) band pass and \pm 100 $\mu \mathrm{V}$ full scale sensitivity and 256 points per trial over a $10.24 \mathrm{~ms}$ sampling period. Data were averaged on a Med 80 miniprocessor (Nicolet Instrument Corp., Madison, WI) utilizing 40- $\mu$ s sampling rates. Averaged traces were then displayed on a 5110 oscilloscope (Tektronix, Inc., Beaverton, OR), stored on magnetic single density floppy disks and printed on a 7010 B X-Y plotter (Hewlett-Packard Co., Palo Alto, CA). Acoustic stimuli consisted of unfiltered rarefaction clicks (duration $120 \mu \mathrm{s}$ ) delivered free field through a modified Audio-Technics ATH5 loudspeaker (K Electronics, Ottawa, Ontario) facing the forehead. Sound intensities measured at the pinna level with a 2209 precision sonometer (Bruel and Kjaer Instruments, Inc., Marlbourough, MA) were determined from 108 $\mathrm{dB}$ sound pressure level (SPL) (re 20 micropascals) to the threshold (the sound intensity which cannot induce two reproducible waveforms). Latencies and amplitudes of the four prominent waves were measured at four different sound intensities $(108,78,45$, and $25 \mathrm{~dB} \mathrm{SPL})$ as well as near threshold.

Histological study. After the last recording, each rat received a lethal dose of barbiturate (sodium pentobarbital $400 \mathrm{mg} / \mathrm{kg}$ i.p.) and was decapitated. Both cochleae were immediately perfused with $1 \% \mathrm{OsO}_{4}$ solution. The cochleae were dissected under a stereomicroscope (Wild Heerbrug Instruments, Inc., Farmingdale, NY) under a constant irrigation with cold glutaraldehyde $(0.1 \mathrm{M})$ followed by a post fixation with $\mathrm{OsO}_{4}$ $(1 \%)$ in phosphate buffer. After a progressive dehydration in ethyl-alcohol, specimens were embedded in epoxy (Epon 300; Micro Biological Supplies, Thornhill, Ontario) and trimmed for surface preparation and for electron microscopy (23).

Morphology was evaluated using a microscope (E. Leitz, Inc., Rockleigh, NJ) with polarized light. The whole length of each cochlea $(9 \pm 0.4$ $\mathrm{mm}$ ) was analyzed for hair cell loss. Selected areas (vicinity of cell losses and samples from undamaged zones) were prepared for electron microscopy in ultrathin sections (LKB III ultramicrotome; LKB Instruments, Inc., Gaithersburg, MD) and counterstained with uranyl acetate and lead citrate.

\section{Gentamicin assays}

Tissue homogenates were centrifuged for $2 \mathrm{~min}$ at $12,000 \mathrm{~g}$ and gentamicin levels were measured in the supernatant fraction. In preliminary control studies, the recovery of the drug in the supernatant had been determined. When known amounts of ${ }^{3} \mathrm{H}$-gentamicin were homogenized with ear, kidney, or liver tissues, $97 \pm 1 \%$ of the drug was found in the supernatant in each case. For the present study, gentamicin content was analyzed with a commercial radioimmunoassay kit (Diagnostic Products Corp., Los Angeles, CA). It was modified according to Meulemans et al. (24) to a sensitivity of $30 \mathrm{pg}$ of gentamicin assay per tube. Based on this sensitivity and the amounts of tissue or fluid sampled, the detection limits were $1 \mathrm{ng} / \mathrm{ml}$ of plasma, $6 \mathrm{ng} / \mathrm{ml}$ of perilymph, $200 \mathrm{ng} / \mathrm{ml} \mathrm{of}$ endolymph, $5 \mathrm{ng} / \mathrm{mg}$ protein for ear tissue, and $0.1-1 \mathrm{ng} / \mathrm{mg}$ protein for other tissue.

\section{Other analytical procedures}

$\mathrm{Na}$ and $\mathrm{K}$ concentrations in endolymph samples were measured by flame spectrophotometry (model 143; Instrumentation laboratory Inc., Lex- 
ington, MA), the sensitivity limit of which was $8 \mathrm{mmol} /$ liter for either ion. Since the normal values for endolymphatic $\mathrm{K}$ and $\mathrm{Na}$ are reported to be $154 \mathrm{mM} /$ liter and $0.91 \mathrm{mM} /$ liter, respectively (25), this method could accurately determine the $\mathrm{K}$ concentration and detect $\mathrm{Na}$ in the specimen if contamination by blood or perilymph exceeded $5 \%$. Accordingly, any sample with detectable $\mathrm{Na}$ was discarded. Protein contents were determined in tissues by the Lowry technique (26).

\section{Calculations}

Because net weight determinations of fresh inner ear samples are problematic, all concentrations are given in micrograms per milligrams of protein. Plateau levels were identified by sight and calculated as the mean of all values involved. Half-lives of the drug were determined from the data by computer-calculated regression curves. Results are expressed as mean \pm SEM. The electrophysiological factorial design was analyzed according to the standard statistical procedure using analyses of variances and covariances (27).

\section{Results}

\section{Gentamicin kinetics}

Group I (single injections). After a single injection of $10 \mathrm{mg} / \mathrm{kg}$, gentamicin concentration peaked in plasma at $12.7 \pm 1.3 \mu \mathrm{g} / \mathrm{ml}$ $30 \mathrm{~min}$ after the injection. The concentration then decreased rapidly. From the early points, i.e., up to $3 \mathrm{~h}$, a $\mathrm{t}_{\frac{1}{2}}$ of $43 \mathrm{~min}$ was calculated while the subsequent phases of disappearance were not determined because of the limited number of data points. In the inner ear, no drug could be detected either in organ of Corti or in lateral wall throughout the experiment. In renal cortex, gentamicin concentration peaked at $0.84 \pm 0.07 \mu \mathrm{g} / \mathrm{mg}$ of protein $6 \mathrm{~h}$ after the injection and decreased with a $\mathrm{t}_{\frac{1}{2}}$ of $\sim 60$ $h$. In lung, the concentration peaked at $0.05 \pm 0.01 \mu \mathrm{g} / \mathrm{mg}$ of protein $3 \mathrm{~h}$ after the injection and decreased with a $t_{1}$ of $2 \mathrm{~h}, 47$ min. In liver, spleen, and heart, gentamicin could not be detected. In this subgroup, kinetics were not assessed in labyrinthine fluids.

After a single injection of $100 \mathrm{mg} / \mathrm{kg}$, gentamicin concentration peaked in plasma at $168 \pm 3 \mu \mathrm{g} / \mathrm{ml} 30 \mathrm{~min}$ after the injection. The concentration then decreased rapidly and from the early points, i.e., up to $3 \mathrm{~h}$, a $\mathrm{t}_{\frac{1}{\mathrm{t}}}$ of about 39 min was calculated. The limited number of samples precluded a correct determination of the further phases of disappearance. In the tissues of the inner ear, the concentration at $3 \mathrm{~h}$ was $0.06 \pm 0.01 \mu \mathrm{g} / \mathrm{mg}$ of protein in both organ of Corti and lateral wall. The concentrations then declined with $a t_{\frac{1}{2}}$ of 13.3 and $10.6 \mathrm{~h}$ in the organ of
Corti and the lateral wall, respectively. At $5 \mathrm{~d}$, gentamicin was undetectable. In renal cortex, gentamicin concentration peaked at $4.06 \pm 0.23 \mu \mathrm{g} / \mathrm{mg}$ of protein $6 \mathrm{~h}$ after the injection and declined with a $t_{\frac{1}{2}}$ of $\sim 57 \mathrm{~h}$. In liver, it peaked at $0.06 \pm 0.003 \mu \mathrm{g} / \mathrm{mg}$ of protein $6 \mathrm{~h}$ after the injection and declined with a $\mathrm{t}_{\frac{1}{2}}$ of $\sim 18 \mathrm{~h}$, $30 \mathrm{~min}$. In spleen, it peaked at $0.075 \pm 0.007 \mu \mathrm{g} / \mathrm{mg}$ of protein $6 \mathrm{~h}$ after the injection and declined with $\mathrm{t}_{\frac{1}{2}}$ of $\sim 22 \mathrm{~h}, 30 \mathrm{~min}$. In lung, it peaked at $0.093 \pm 0.002 \mu \mathrm{g} / \mathrm{mg}$ of protein $3 \mathrm{~h}$ after the injection and declined with a $t_{1}$ of $3 \mathrm{~h}, 15 \mathrm{~min}$. In this subgroup, kinetics were not assessed in labyrinthine fluids.

Group II (constant infusion). In plasma, the concentrations plateaued after $1 \mathrm{~h}$ at values which depended on the rate of gentamicin delivery. They were $0.90 \pm 0.12,2.4 \pm 0.27,14.7 \pm 2$, and $164.6 \pm 30 \mu \mathrm{g} / \mathrm{ml}$ in subgroups a, b, c, and d, respectively. This steady state plateau was sustained up to the development of renal insufficiency, as determined by an increased BUN in the samples collected before sacrifice. This occurred at days 12 , 10 , and 2 in the last three subgroups, respectively.

In inner ear, the results were strikingly similar for both the organ of Corti (Fig. 1) and the lateral wall (Fig. 2). The concentrations increased up to plateau values, which seemed to be reached within $3 \mathrm{~h}$. In subgroup a, it was $0.08 \pm 0.02$ and $0.07 \pm 0.01 \mu \mathrm{g} / \mathrm{mg}$ of protein, respectively. In subgroup b, it was $0.12 \pm 0.02$ and $0.18 \pm 0.07 \mu \mathrm{g} / \mathrm{mg}$ of protein, respectively. In subgroup $c$, it was $0.87 \pm 0.15$ and $0.96 \pm 0.24 \mu \mathrm{g} / \mathrm{mg}$ of protein, respectively. In subgroup $d$, the plateau value was the same as that of subgroup c, indicating that a saturation had been achieved. The plateau values in tissues were directly related to the plasma levels only for the first three subgroups, and only before the development of a renal insufficiency with its related increased plasma gentamicin concentration.

In perilymph, the concentrations seemed to be related to the infusion rates (Fig. 3). For the duration of the experiments and for all subgroups, the perilymph to plasma ratios of gentamicin concentrations ranged from 0.05 to 0.24 . When considering all the perilymph samples collected at $12 \mathrm{~h}$, a linear relationship was observed between the mean perilymph concentration and the plasma level for all infusion rates ranging from 1.5 to 150 $\mu \mathrm{g} / \mathrm{min}(y=0.029 x+0.32, r=0.99, P<0.001)$.

In endolymph (Fig. 4), results showed that: $(a)$ the higher the infusion rate, the earlier the detection of the drug. Gentamicin was detected at $6 \mathrm{~h}$ in subgroup d (although one sample showed a detectable amount at $1 \mathrm{~h}$ ), at $12 \mathrm{~h}$ in subgroups $\mathrm{c}$ and $\mathrm{b}$, and at $2 \mathrm{~d}$ in subgroup a. (b) In subgroups $\mathrm{a}, \mathrm{b}$, and $\mathrm{c}$ gentamicin

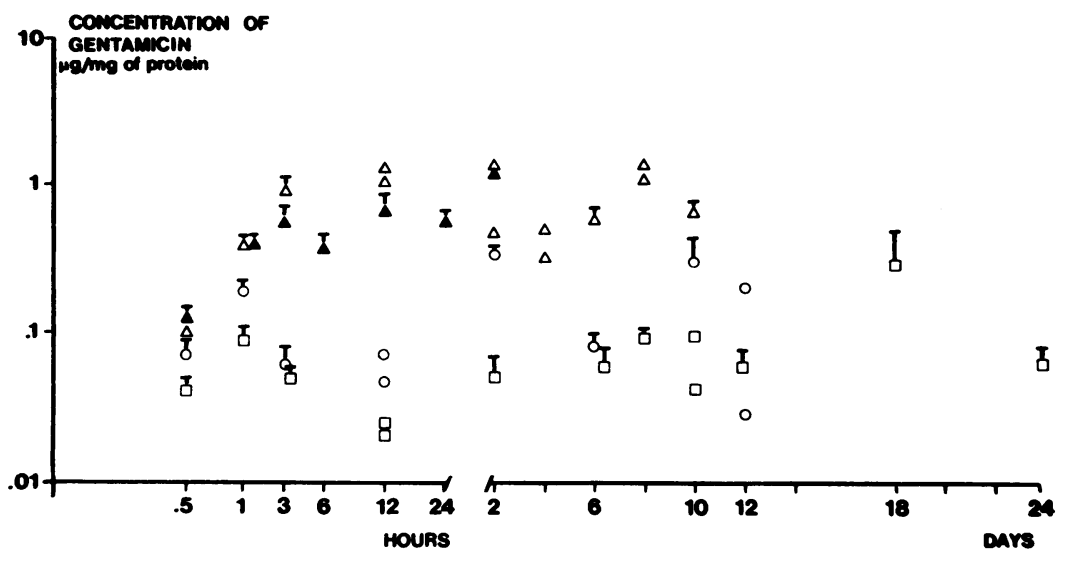

Figure 1. Kinetics of gentamicin in the organ of Corti during constant infusion of $1.5(\square), 4.5(0), 15(\Delta)$, and $150(\triangle) \mu \mathrm{g} / \mathrm{min}$ of gentamicin. Vertical bars indicate the SEM of at least three samples. Note the double scale used in the abscissae. 


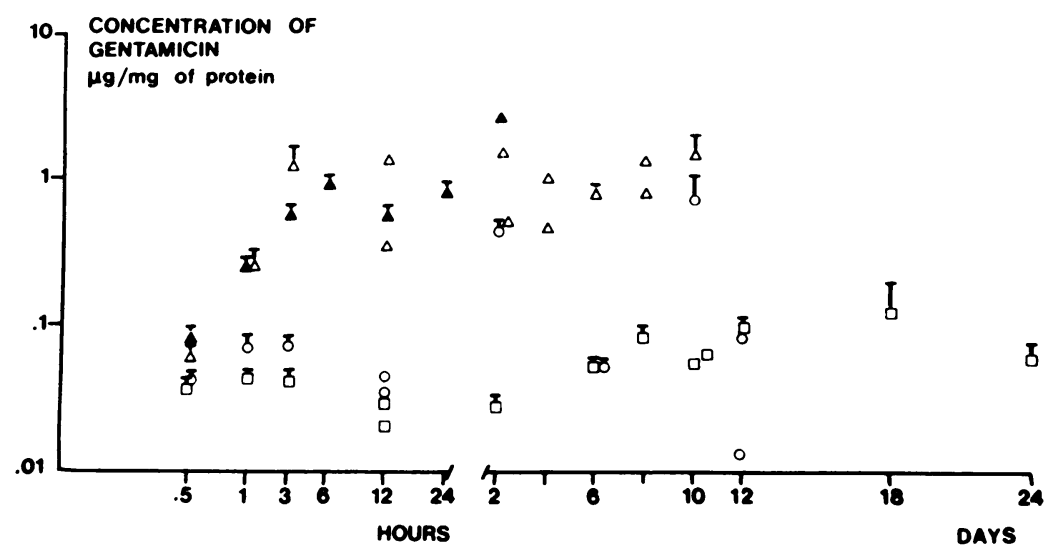

Figure 2. Kinetics of gentamicin in the lateral wall during constant infusion of $1.5(\square), 4.5(0), 15(\Delta)$, and 150 (A) $\mu \mathrm{g} / \mathrm{min}$ of gentamicin. Vertical bars indicate the SEM of at least three samples. Note the double scale used in the abscissae. was undetectable in some animals after the time of its first detection. (c) When measurable, the concentrations in the first three subgroups remained low, averaging $1 \mu \mathrm{g} / \mathrm{ml} .(d)$ in subgroup d, the concentrations seemed to increase with time.

In renal cortex, the kinetics were similar to that observed in inner ear tissues. The saturation levels in subgroups $c$ and $d$, however, were not achieved until $24 \mathrm{~h}$ and then reached a value 10 -fold higher than in the cochlea, i.e., about $10 \mu \mathrm{g} / \mathrm{mg}$ of protein. In subgroups $a$ and $b$, the saturation levels achieved by $2 \mathrm{~d}$ were 2.17 and $5.6 \mu \mathrm{g} / \mathrm{mg}$, respectively.

In spleen, the concentrations appeared to be related to the infusion rates. Except for the slowest rate of infusion (subgroup IIa) where a steady state plateau was reached, no saturation seemed to develop over the course of the experiment. It must be observed, however, that, despite a careful washing of the vascular bed before dissection, a contamination by blood cannot be ruled out.

In liver and heart, the scatter of the experimental points precluded a precise assessment of the pharmacokinetics. It seemed, however, that in both organs concentrations plateaued at values that increased as a function of the infusion rates. When for each infusion rate all points at and after the plateau were pooled, the following values were determined: in liver, $0.018 \pm 0.002,0.02 \pm 0.002,0.033 \pm 0.005$, and $0.09 \pm 0.04 \mu \mathrm{g} / \mathrm{mg}$ of protein, for subgroups IIa, IIb, IIc, and IId, respectively; in heart, $0.014 \pm 0.003,0.016 \pm 0.003,0.07 \pm 0.02$, and $0.09 \pm 0.02 \mu \mathrm{g} /$ mg of protein, respectively. In this series, half of the lung samples were lost during technical manipulation; this loss precluded any analysis.

Group III (release). In the 34 animals of subgroup IIIa, the release of gentamicin was studied for $30 \mathrm{~d}$ after the end of a 3$\mathrm{h}$ infusion of $15 \mu \mathrm{g} / \mathrm{min}$ (Table I). In plasma, the concentrations were $11.8 \pm 1.2 \mu \mathrm{g} / \mathrm{ml}$ at the cessation of the infusion and $0.16 \pm 0.03 \mu \mathrm{g} / \mathrm{ml}$ at $24 \mathrm{~h}$, indicating a rapid decline compatible with that observed in group $\mathrm{I}$. The rest of the plasma curve appeared to be biexponential, and when the points were analyzed according to a bicompartmental model, two phases were determined with half-lives (days) of $1(r=0.59)$ and $16.9(r=0.534)$, respectively. In all organs but the inner ear, the curves were assumed to be monoexponential. According to this assumption, the half-lives (days) were: 5.6 in renal cortex $(r=0.945), 4.4$ in liver $(r=0.934), 3.9$ in heart $(r=0.899), 6.6$ in lung $(r=0.797)$, and 4.6 in spleen $(r=0.729)$. In cochlear tissues (Fig. 5), the organ of Corti was not separated from the lateral wall. Because the earlier results had shown the similarity of the concentrations achieved in the two structures, they were pooled for the assay in this subgroup. The concentration was $0.56 \pm 0.05 \mu \mathrm{g} / \mathrm{mg}$ of protein at the end of the infusion and $0.043 \pm 0.01 \mu \mathrm{g} / \mathrm{mg}$ of protein $24 \mathrm{~h}$ later, indicating a rapid initial phase of disappearance with a $t_{\frac{1}{2}}$ of about $6 \mathrm{~h}, 15 \mathrm{~min}$. From the later time points, a slower second phase was then determined with a $t_{\frac{1}{2}}$ of $7.3 \mathrm{~d}(r$ $=0.527$ ).

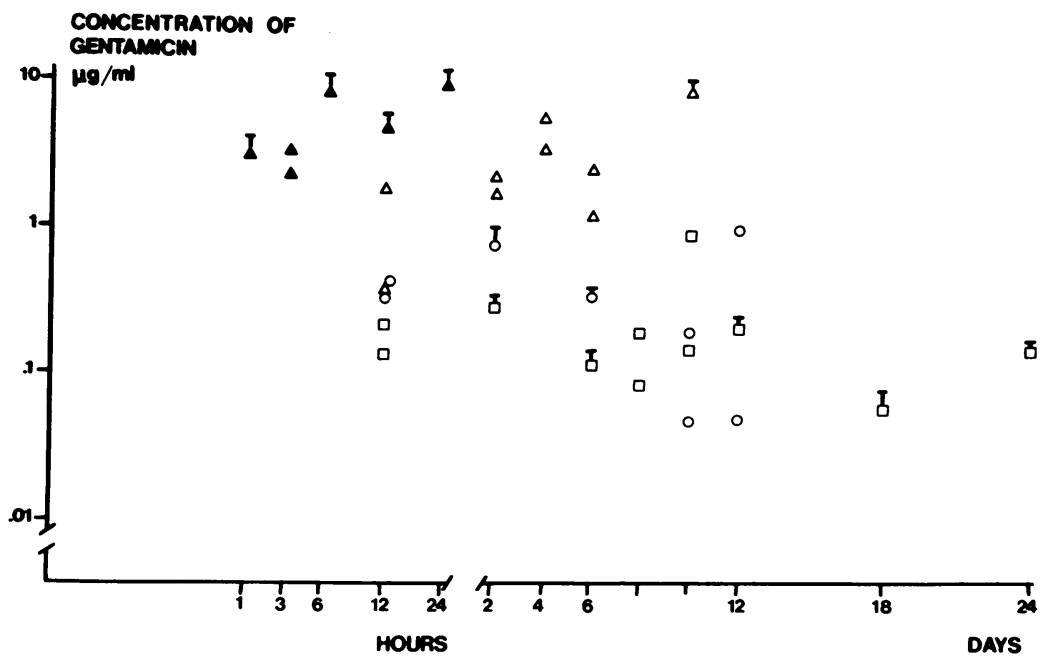

Figure 3. Kinetics of gentamicin in perilymph during constant infusion of $1.5(\square), 4.5(0), 15(\Delta)$, and 150 (ム) $\mu \mathrm{g} / \mathrm{min}$ of gentamicin. Vertical bars indicate the SEM of at least three samples. Note the double scale used in the abscissae. 


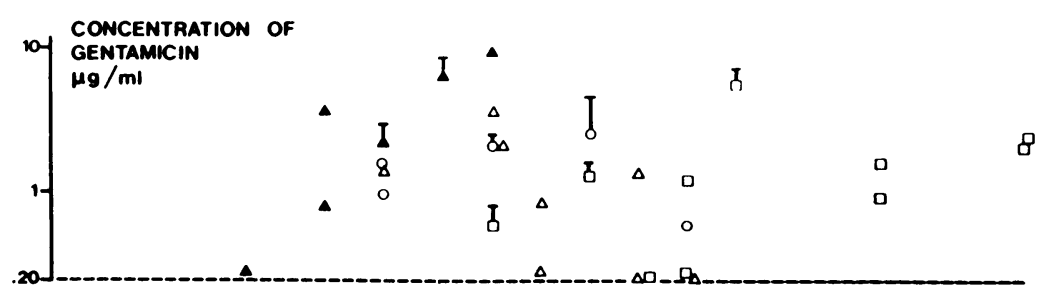

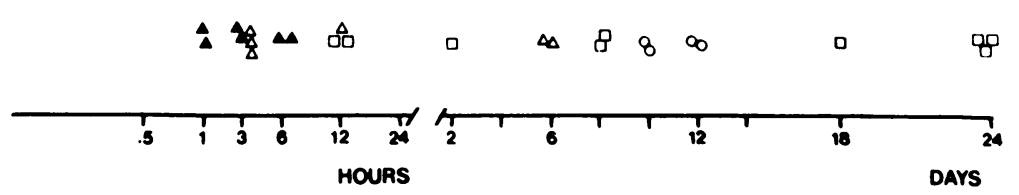

Figure 4. Kinetics of gentamicin in endolymph during constant infusion of $1.5(\mathrm{D}), 4.5(\mathrm{O}), 15(\Delta)$, and 150 (৯) $\mu \mathrm{g} / \mathrm{min}$ of gentamicin. Vertical bars indicate the SEM of at least three samples. Note the double scale used in the abscissae. The horizontal dashed line indicates the sensitivity limit.
In the 40 animals of subgroup IIIb, the disappearance of gentamicin was studied for $30 \mathrm{~d}$ after $30 \mathrm{~d}$ of a daily $100 \mathrm{mg} /$ kg i.m. injection. In plasma, the curves were best fitted according to a bicompartmental model and two phases were determined with half-lives (days) of $2.0(r=0.587)$ and $17.5(r=0.594)$, respectively. In all organs, the release seemed to be monoexponential. According to this assumption, the half-lives (days) were 14.5 in renal cortex $(r=0.778), 10.7$ in liver $(r=0.932)$, 14.2 in heart $(r=0.779), 18.2$ in lung $(r=0.794), 24.1$ in spleen $(r=0.635), 34.6$ in organ of Corti $(r=0.597)$, and 38 in lateral wall $(r=0.789)$.

In both subgroups, the disappearance of gentamicin from perilymph exhibited a similar pattern. In subgroups $a$ and $b$, the initial values were $0.12 \pm 0.04$ and $0.15 \pm 0.06 \mu \mathrm{g} / \mathrm{ml}$, and the final ones at day $30,0.06 \pm 0.01$ and $0.18 \pm 0.08 \mu \mathrm{g} / \mathrm{ml}$, respectively.

In subgroup IIIa, as expected, no gentamicin was present in endolymph at day 0 , i.e., at the end of the 3-h infusion period. In the five following days, however, the drug was detected in all but four samples. Levels were $1.7 \pm 0.9 \mu \mathrm{g} / \mathrm{ml}$ at day 1 , and $0.37 \pm 0.02 \mu \mathrm{g} / \mathrm{ml}$ at day 5 . Thereafter gentamicin was undectectable. In subgroup IIIb the drug was undetectable in about half the samples. In the remaining samples the concentrations ranged from 0.38 to $3 \mu \mathrm{g} / \mathrm{ml}$ over $30 \mathrm{~d}$.

\section{Electrolytes, protein, and BUN measurements}

The concentration of $\mathrm{K}$ in endolymph was $151.3 \pm 4.5 \mathrm{mM}$ ( $n$ $=142$ ) and the concentration of $\mathrm{Na}$ was always lower than the detection limit.

The protein content per gram of wet tissue averaged $173 \pm 11$ $\mathrm{mg}$ for renal cortex, $193 \pm 12 \mathrm{mg}$ for liver, $108 \pm 17 \mathrm{mg}$ for lung, $138 \pm 17 \mathrm{mg}$ for spleen, and $157 \pm 10 \mathrm{mg}$ for heart.

In group I and IIa, BUN measurements were in the range of the normal values found in our laboratory, i.e., $120-220 \mathrm{mg} /$ liter. As mentioned above, a marked increase was noticed in subgroups IIb, IIc, and IId at the time of sacrifice, while values obtained at the time of minipump reimplantation were normal. In group III, measurements were in the normal range throughout the experiment. In subgroup IIIb, this contrasted with a marked swelling of the kidneys found at the time of dissection.

\section{Electrophysiological and histological studies}

The electrophysiological responses show that animals receiving a single dose of $100 \mathrm{mg} / \mathrm{kg}$ (subgroup IVc) or a 3-h constant infusion of $15 \mu \mathrm{g} / \mathrm{min}$ (subgroup IVa) did not exhibit significant changes at any time as compared with control animals (Fig. 6). Latencies, amplitudes, and thresholds exhibited negligible individual variations $(P>0.5)$.

However, animals injected daily for $30 \mathrm{~d}$ (subgroup IVb) showed significant changes as compared with control animals. As a result of the well known delay in action of aminoglycosides, amplitudes continued to decrease after the end of injections $(P$ $<0.001$ for all waves). Thresholds elevated progressively from the second month, with no responses being elicited at $78 \mathrm{~dB}$ SPL at the end of the evaluations (Fig. 6). Conversely, controls had obvious responses at $10 \pm 7 \mathrm{~dB}$ SPL $(P<0.0001)$. Finally, latencies progressively lengthened in treated animals from the middle of the second month of the experiment. Differences to controls were evident on the last recording for all waves $(P<0.01)$.

This pattern of pathology was confirmed in the histological study. Subgroups IVa, IVc, and IVd exhibited normal cytocochleograms (Fig. 7, right). Scattered missing hair cells were within the range of controls, as were apical alterations. Furthermore, electron microscopic evaluation failed to detect any

Table I. Half-lives of Disappearance (in Days)

\begin{tabular}{lll}
\hline Tissues & $\begin{array}{l}\text { After 3-h infusion of } \\
30 \mu \mathrm{g} / \mathrm{min} \text { (IIIa) }\end{array}$ & $\begin{array}{l}\text { After } 30 \mathrm{~d} \text { of daily } \\
100 \mathrm{mg} / \mathrm{kg} \text { i.m. } \\
\text { injection (IIIb) }\end{array}$ \\
\hline Plasma & $1-16.9^{*}$ & $2-17.5^{*}$ \\
Renal cortex & 5.6 & 14.5 \\
Liver & 4.4 & 10.7 \\
Heart & 3.9 & 14.2 \\
Lung & 6.6 & 18.2 \\
Spleen & 4.6 & 24.1 \\
Cochlear tissues & $0.25-7.3^{*}$ & \\
Organ of Corti & & 34.6 \\
Lateral wall & & 38
\end{tabular}

Half-lives of disappearance of gentamicin from plasma and tissues in group III.

* A bicompartmental analysis was made.

$¥$ Organ of Corti and lateral wall were pooled. 


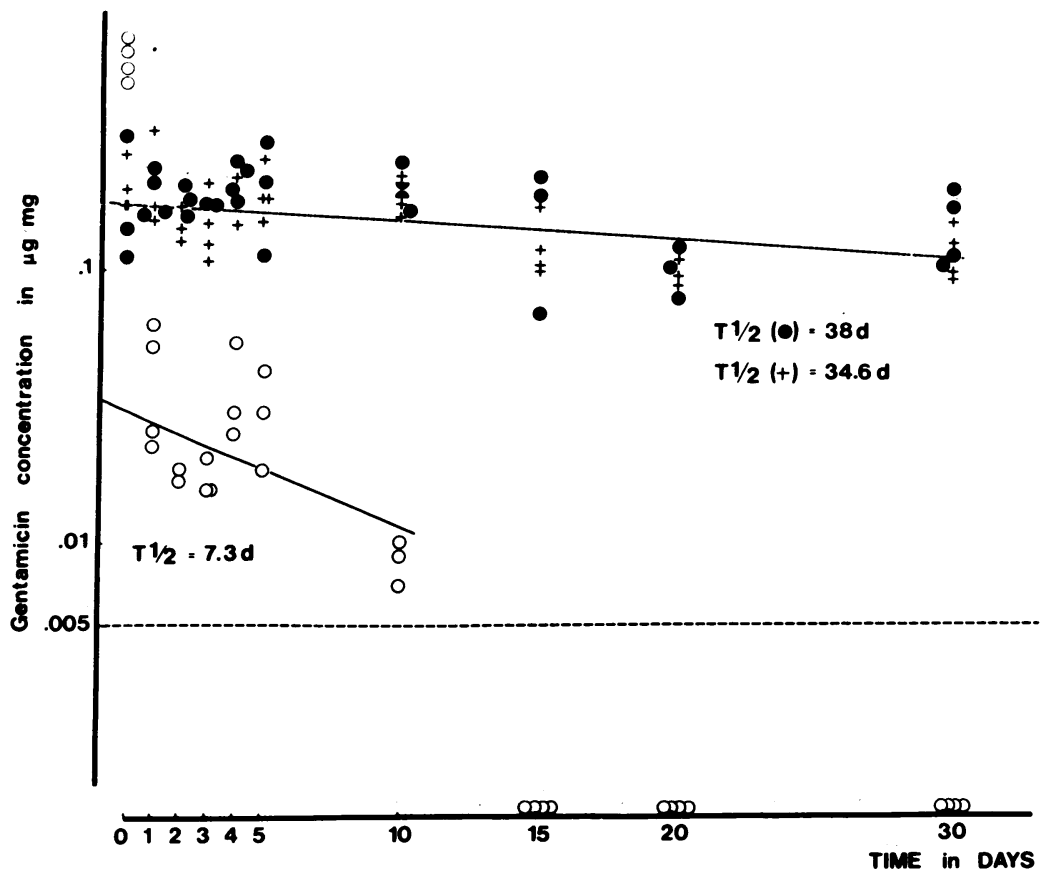

Figure 5. Disappearance of gentamicin from the cochlear tissues. (o) Values obtained from the combined organ of Corti and the lateral wall tissues following a 3-h constant infusion of $15 \mu \mathrm{g} / \mathrm{min}$ of gentamicin. $(+)$ and $(\bullet)$ Values obtained from the organ of Corti and from the lateral wall, respectively, after $30 \mathrm{~d}$ of a daily $100 \mathrm{mg} / \mathrm{kg}$ i.m. injection of gentamicin. The horizontal dashed line indicates the sensitivity limit.

abnormality related to aminoglycoside ototoxicity. Envelopes, cytoplasms, nuclei, and nerve endings looked normal.

In contrast, rats given $100 \mathrm{mg}$ of gentamicin daily for $30 \mathrm{~d}$ (subgroup IVb) had widespread hair cell losses, predominantly in the third row of outer hair cells (Fig. 7, left), although some variations in pattern existed. Amid spared cells, all stages of aminoglycoside-induced damage, ranging from irregularities in the smooth endoplasmic reticulum or damaged mitochondria to massive swelling with rupture at the cuticular pore, were observed with an electron microscope.

It was concluded that neither a single injection of $100 \mathrm{mg} /$ $\mathrm{kg}$ i.m. nor continuous 3-h infusion with $15 \mu \mathrm{g} / \mathrm{min}$ gentamicin seemed to influence either electrical activity or anatomical structure of the cochlea. In contrast, daily injections of $100 \mathrm{mg} /$ kg gentamicin for $\mathbf{3 0 ~ d}$ induced typical signs of ototoxicity.

\section{Discussion}

From the experiments with continuous infusion, it appeared that the uptake of gentamicin into the tissues of the inner ear proceeded by a mechanism which yielded early steady state levels and manifested rapid saturation kinetics. For low infusion rates, and as long as no renal failure developed, tissue levels seemed to be related to plasma levels, suggesting that the uptake of the drug by the tissues of the inner ear was concentration dependent and, thus, dose dependent. This would agree with the kinetics of aminoglycosides in kidney where the fractional absorption is constant within a given range of filtered load (28). For infusion rates yielding plasma concentrations of $15 \mu \mathrm{g} / \mathrm{ml}$ and more, tissue concentrations plateaued, suggesting that a saturation had occurred.

The low ratio of the perilymph and endolymph to plasma concentrations throughout the duration of the experiment, along with the saturation in the tissues at relatively low drug levels, strongly argue against the concept of an unrestricted accumulation of the drug in the inner ear, which has long been considered $(3,6,9,29)$ a basic mechanism of the organ specificity of aminoglycoside toxicity.

The polycationic aminoglycosides have been shown to bind to anionic sites of membranes such as acidic phospholipids, and to possess a particularly high affinity to polyphosphoinositides considered to be present in the inner leaflet of the plasma membrane (30-33). Recent experiments of gentamicin toxicity in cochlear perfusions have also suggested that, as in the kidney (34-37), the drug may be taken up into the cell by an active transport mechanism (38). The rapid uptake observed in the present study agrees with a strong affinity of gentamicin for its cellular binding sites; the early saturation could be the conse-
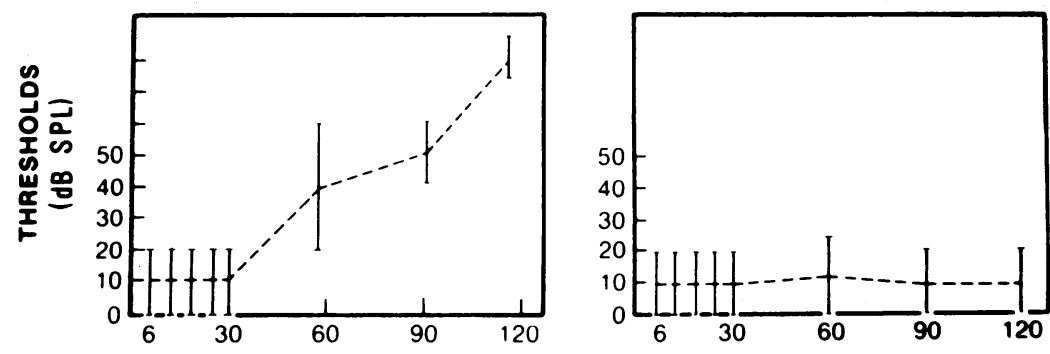

Figure 6. Evolution of the thresholds of the auditory evoked potentials during and after the course of gentamicin treatment. (Right) subgroup IVa given a 3-h constant infusion of $15 \mu \mathrm{g} / \mathrm{min}$. (Left) subgroup IVb given a daily $100 \mathrm{mg} / \mathrm{kg}$ i.m. injection for $30 \mathrm{~d}$. Mean values are plotted plus or minus two standard deviations. Abscissae, time in days. Day 0 corresponds to the end of the infusion period in subgroup IVa and to the beginning of the treatment period in subgroup $\mathrm{IVb}$. Ordinates, thresholds in $\mathrm{dB}$ SPL. Note that in subgroup IVb thresholds elevate after cessation of the treatment period. 

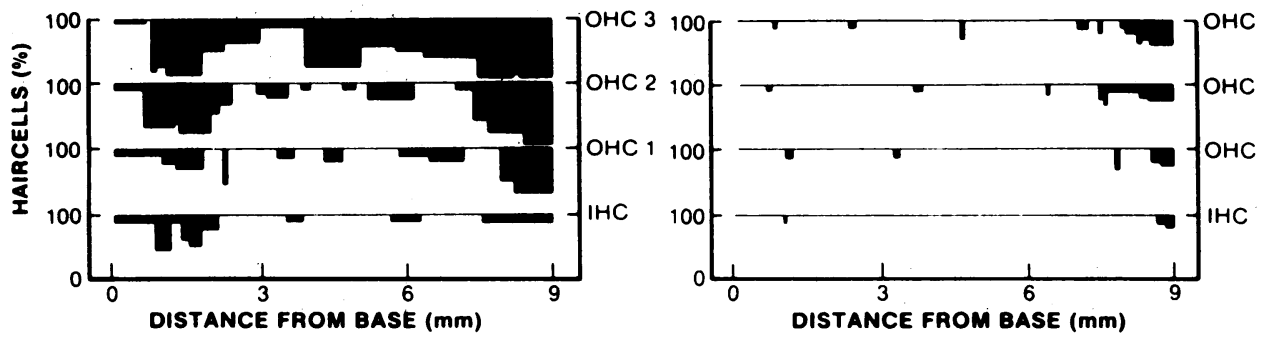

Figure 7. Histological study. Two different patterns of alterations are observable. Percentages of missing cells are represented in black. OHC, outer hair cells ( 3 rows). IHC, inner hair cells (1 single row). The left cytocochleogram shows typical damages occurring in most of rats of group IVb (daily $100 \mathrm{mg} / \mathrm{kg}$ i.m. injection during $30 \mathrm{~d}$ ). Extensive losses are

present in almost the whole third row of OHC and in apical and basal parts of the other hair cells. Conversely, the right cytocochleogram is typical from the three other experimental designs: 3-h constant infusion of $15 \mu \mathrm{g} / \mathrm{mn}$ (subgroup IVa), single $100 \mathrm{mg} / \mathrm{kg}$ i.m. injection (subgroup IVc), or saline injection (subgroup IVd). No hair cell damages are elicited. Note: missing hair cells close to the apex are currently observed even in normal animal, as a result of aging process.

quence of a limited binding capacity. However, the data are also compatible with the existence of an active uptake system.

Comparison with the kinetics in other body organs provides the following information. First, in renal cortex, the kinetics of drug uptake is similar to that of the inner ear tissues and saturation is also observed. However, the concentrations achieved are higher than in the inner ear by one order of magnitude. Such a discrepancy between two organs that demonstrate a similar susceptibility to gentamicin remains difficult to elucidate. In the kidney, high drug concentrations are found in the lysosomes of proximal tubular cells (34-37) but no information is available on the cellular or subcellular distribution in the inner ear. The present study only analyzed the major tissues of the cochlea, and the technical limitations "of the autoradiographic investigations performed so far (39-41) preclude a precise mapping of the cochlear structures with regard to the location of the drug. Accordingly, no conclusion can be drawn as to whether the levels of aminoglycoside concentrations achieved in a given cell type may be directly related to the development of toxicity.

Second, in other organs, the scatter of the data precluded definite conclusions. In addition, results from spleen must be considered with caution since the possibility of contamination with blood cannot be disregarded. In liver or heart, the concentrations plateaued at values which increased as a function of infusion rates, suggesting that the uptake of the drug is concentration dependent. In contrast to inner ear and kidney, however, the rate of uptake was markedly slow, suggesting a poor affinity of gentamicin for the binding sites of these organs, and no saturation could be demonstrated within the duration of the experiment.

The release of the drug from the tissues of the inner ear was measured to determine whether the pattern of disappearance differed depending on the duration of drug treatment and on the presence or absence of ototoxicity. Accordingly, the elimination kinetics were studied after three ways of loading, yielding either high but brief peak plasma levels (group I); early saturation levels in the tissues, but no functional impairment (subgroup IIIa); or persistent saturation levels with electrophysiological and histological evidences of toxicity (subgroup IIIb). It may be observed that the levels achieved in cochlear tissues by the end of the 3-h infusion in subgroup IIIa were somewhat lower than those found in subgroup IIc, i.e., $0.56 \mu \mathrm{g} / \mathrm{mg}$ vs. about $0.94 \mu \mathrm{g} /$ mg. Such a discrepancy may be accounted for by the fact that studies and analyses were conducted over a period of $3 \mathrm{yr}$, leading to occasional mismatchings between results.

Under these experimental conditions, the disappearance of gentamicin from the organ of Corti and the lateral wall exhibited three phases which, most probably, reflected different stages of compartmentation or different binding states. The first phase is demonstrated by the release curve of group I and by the initial slope in subgroup IIIa, and shows a $t_{\frac{1}{2}}$ of $\sim 10 \mathrm{~h}$. The second phase demonstrated by the second slope in subgroup IIIa with a $t_{1}$ of about $7 \mathrm{~d}$ may be compared with that in renal cortex, i.e., $5.6 \mathrm{~d}$, where the drug is known to accumulate within lysosomes $(42,43)$. However, our analysis at the tissue level cannot give information as to the localization of this potential second binding site in the cochlear structures. The absence of ototoxicity, as shown by electrophysiological and histological data, indicates that the drug has not yet interfered with crucial steps of cell metabolism. The third phase demonstrated in subgroup IIIb has a $t_{1}$ of over $30 \mathrm{~d}$. This resulted in drug concentrations higher in cochlear tissues than in other body tissues (except in renal cortex) $30 \mathrm{~d}$ after the last injection. In this group, the drug has exerted its noxious effects as evidenced by the effects on brain stemevoked activity and loss of hair cells. It is possible that the release of gentamicin is due to the disintegration of intoxicated cells rather than to a binding equilibrium. The sensory cells of the cochlea do not regenerate, while cells of the lateral wall $(44,45)$ or of the renal cortex $(46,47)$ do. This may explain why, despite similar drug concentrations, damage to the sensory structures is usually irreversible, while a strial or renal deficiency may recover. Indeed, reversible electrophysiological (48) or audiometric (49, 50) changes have been reported in animals or in humans after administration of various aminoglycosides. Such a reversibility, however, which suggests a transient alteration of the hair cells, was observed only after doses lower than those used in our subgroup IIIb.

The observation that manifestation of ototoxicity seems to be associated with the penetration of the drug into deep compartment(s) agrees with biochemical (51) and electrophysiological $(48,52-54)$ investigations showing that aminoglycosides interact in a time- and dose-dependent manner with the sensory structures.

Single injections of 10 or $100 \mathrm{mg} / \mathrm{kg}$ i.m. yielded no drug in the inner ear or concentrations lower than those observed after a 3-h constant infusion of $15 \mu \mathrm{g} / \mathrm{min}$ (corresponding to $\sim 10$ $15 \mathrm{mg} / \mathrm{kg}$ ). This demonstrates that the mode of administration markedly influences the drug uptake. Thus, the levels of gentamicin concentrations achieved in cochlear tissues depend on plasma concentrations as a function of time. This observation must be considered in light of the recent finding by Davis et al. (55) that the magnitude of kanamycin ototoxicity is related to the total daily dose alone and not to the dosing schedule. Anyhow, it leads one to consider the role of the labyrinthine fluids, 
which represent the obligatory route of access for a drug to the sensory structures (56), and, thus, an intermediate compartment that directly influences the uptake.

The present study demonstrates that drug concentrations in the labyrinthine fluids do not directly correlate to those in cochlear tissues, and, therefore, cannot represent any index of toxicity as it has previously been postulated $(3,6)$. It also suggests that perilymph, probably via cortilymph (57), is the main route of access for the aminoglycosides to the sensory structures. While the organ of Corti is saturated in $3 \mathrm{~h}$, gentamicin is not yet detectable in endolymph regardless of the infusion rates. The present data also confirm our previous findings $(13,14)$ that: (a) neither an accumulation nor a threshold for drug entry exists for perilymph, $(b)$ the perilymphatic concentrations are related to plasma concentrations whatever the infusion rate, $(c)$ gentamicin appears in endolymph later than in perilymph, and $(d)$ the persistence of the drug in both fluids after cessation of the administration is probably due to the slow release of the drug from the tissues toward the surrounding fluids.

Comparison of the kinetic data obtained from the different organs shows that rapid uptake, early saturation, and long exposure to the drug are features that occur exclusively in renal and cochlear structures and may account for the development of toxicity. In the inner ear, the surrounding fluids maintain sustained concentration levels of gentamicin in the vicinity of the sensory structures. The rapidity of this uptake, which leads to fast saturation, provides more time for the drug to reach deep compartment(s). This penetration may be related to the expression of noxious effects. Finally, the extremely slow half-life of disappearance from the inner ear tissues demonstrates the very particular handling of gentamicin by the cochlear cells, yielding an almost permanent sequestration of the drug.

\section{Acknowledgments}

The authors are indebted to F. Faurisson who performed some assays for this study and made the statistical analysis of the data; to C. Amiel, F. Carbon, P. Tulkens, C. Vaamonde, and G. Saumon for invaluable discussions of the manuscript; to C. Desrochers, M. Barker, G. Zajic, and $K$. Takada for technical assistance; to $D$. Humes for conducting the BUN analyses; and to F. Carlier for typing the manuscript and making the figures.

This work was supported by research grant NS13792 and program project NS05785 from the National Institutes of Health; by grant 816048 from the Institut National de la Santé et de la Recherche Médicale; and by grant MA-6896 from the Medical Research Council of Canada.

\section{References}

1. Voldrich, L. 1965. The kinetics of streptomycin, kanamycin and neomycin in the inner ear. Acta Otolaryngol. 60:243-248.

2. Vrabec, D. P., D. T. Cody, and J. A. Ulrich. 1965. A study of the relative concentrations of antibiotics in the blood, spinal fluid and perilymph in animals. Ann. Otol. Rhinol. Laryngol. 74:688-705.

3. Stupp, H. F. 1970. Untersuchung der antibiotikaspiegel in den innenohrflüssigkeiten und ihre bedeutung für die spezifishe ototoxizität der aminoglykosidantibiotika. Acta Otolaryngol. 262(Suppl):1-85.

4. Watanabe, Y., R. Nakajima, R. Oda, M. Uno, and T. Naito. 1971. Experimental study on the transfer of kanamycin to the inner ear fluids. Med. J. Osaka Univ. 21:257-263.

5. Wagner, W. H., J. T. Y. Chou, C. Von Ilberg, R. Ritter, and K. H. Vosteen. 1971. Untersuchungen zur pharmakokinetik von streptomycin. Drug. Res. 21:2006-2016.
6. Stupp, H. F., K. Küpper, F. Lagler, H. Sous, and M. Quante. 1973. Inner ear concentrations and ototoxicity of different antibiotics in local and systemic application. Audiology. (Basel) 12:350-363.

7. Von Ilberg, C., W. Arnold, and R. Ritter. 1974. Ursachen und beeinflussung der ototoxizität des streptomycins und verwandter antibiotika. Laryngol. Rhinol. Otol. 53:112-120.

8. Quante, M., P. Strauss, and H. Rosin. 1974. Gentamicin level in the guinea-pig's perilymph and liquor subject to the dosis distribution. Arch. Oto-rhino-laryngol. 208:295-296.

9. Federspil, P., W. Schätzle, and E. Tiesler. 1976. Pharmacokinetics and ototoxicity of gentamicin, tobramycin and amikacin. J. Infect. Dis. 134(Suppl):200-205.

10. Christensen, E. F., J. C. Reiffenstein, and H. Madissoo. 1977. Comparative ototoxicity of amikacin and gentamicin in cats. Antimicrob. Agents Chemother. 12:178-184.

11. Brummett, R. E., K. E. Fox, R. T. Brown, and D. L. Himes. 1978. Comparative ototoxic liability of netilmicin and gentamicin. Arch. Otolaryngol. 104:579-584.

12. Russell, N. J., K. E. Fox, and R. E. Brummett. 1979. Ototoxic effects of the interaction between kanamycin and ethacrynic acid. Acta Otolaryngol. 88:369-381.

13. Tran Ba Huy, P., C. Manuel, A. Meulemans, O. Sterkers, and C. Amiel. 1981. Pharmacokinetics of gentamicin in perilymph and endolymph of the rat as determined by radioimmunoassay. J. Infect. Dis. 143:476-486.

14. Tran Ba Huy, P., A. Meulemans, M. Wassef, C. Manuel, O. Sterkers, and C. Amiel. 1983. Gentamicin persistence in rat endolymph and perilymph after a two-day constant infusion. Antimicrob. Agents Chemother. 23:344-346.

15. Desrochers, C. S., and J. Schacht. 1982. Neomycin concentrations in inner ear tissues and other organs of the guinea-pig after chronic drug administration. Acta Otolaryngol. 93:233-236.

16. Luft, F. C., and S. A. Kleit. 1974. Renal parenchymal accumulation of aminoglycoside antibiotics in rats. J. Infect. Dis. 130:656-659.

17. Fabre, J., M. Rudhardt, P. Blanchard, and C. Regamey. 1976. Persistence of sisomicin and gentamicin in renal cortex and medulla compared with other organs and serum of rats. Kidney Int. 10:444-449.

18. Houghton, D. C., M. N. Hartnett, M. Campbell-Boswell, G. A. Porter, and W. M. Bennett. 1976. A light and electron microscopic analysis of gentamicin nephrotoxicity in rats. Am. J. Pathol. 82:589-600.

19. Schentag, J. J., T. J. Cumbo, W. J. Jusko, and M. E. Plant. 1978. Gentamicin tissue accumulation and nephrotoxic reactions. JAMA (J. Am. Med. Assoc.) 240:2067-2069.

20. Kaloyanides, G. J., and E. Pastoriza-Munoz. 1980. Aminoglycoside nephrotoxicity. Kidney Int. 18:571-582.

21. Cronin, R. E., R. E. Bulger, P. Southern, and W. L. Henrich. 1980. Natural history of aminoglycoside nephrotoxicity in the dog. $J$. Lab. Clin. Med. 95:463-474.

22. Desrochers, C. S., and J. Schacht. 1981. Assay of aminoglycosides is influenced by tissue homogenization technique. Experientia (Basel). 27:1357.

23. Spoendlin, H., and J. P. Brun. 1974. The block surface technique for evaluation of cochlear pathology. Arch. Oto-rhino-laryngol. 208:137145.

24. Meulemans, A., C. Manuel, and P. Tran Ba Huy. 1981. Radioimmunoassay of gentamicin in microliter and nanoliter samples of biological fluids. Chemotherapy. 27:29-33.

25. Bosher, S. K., and R. L. Warren. 1968. Observations on the electrochemistry of the cochlear endolymph of the rat: a quantitative study as determined by means of flame spectrophotometry. Proc. R. Soc. Lond. B. Biol. Sci. 171:227-247.

26. Lowry, O. H., N. J. Rosebrough, A. L. Farr, and R. J. Randall. 1951. Protein measurement with the folin phenol reagent. J. Biol. Chem. 193:265-275.

27. Snedecor, G. W., and W. G. Cochran. 1967. Statistical methods. 6th ed. The Iowa State University Press, Ames, Iowa. 228-298, 419446. 
28. Josepovitz, C., E. Pastoriza-Munoz, D. Timmerman, M. Scott, S. Feldman, and G. J. Kaloyanides. 1982. Inhibition of gentamicin uptake in rat renal cortex in vivo by aminoglycosides and organic polycations. J. Pharmacol. Exp. Ther. 223:314-321.

29. Toyoda, Y., and M. Tachibana. 1978. Tissue levels of Kanamycin in correlation with oto- and nephrotoxicity. Acta Otolaryngol. 86:9-14.

30. Schacht, J. 1979. Isolation of an aminoglycoside receptor from guinea-pig inner ear tissues and kidney. Arch. Oto-rhino-laryngol. 224: 129-134.

31. Lohdi, S. N. D., I. Weiner, I. Mechigian, and J. Schacht. 1980. Ototoxicity of aminoglycosides correlated with their action on monomolecular films of polyphosphoinositides. Biochem. Pharmacol. 29:597601 .

32. Brasseur, R., G. Laurent, M. M. Ruysschaert, and P. Tulkens. 1984. Interactions of aminoglycoside antibiotics with negatively charged lipid layers. Biochem. Pharmacol. 33:629-637.

33. Sastrasinh, M., T. C. Knauss, J. M. Weinberg, and H. D. Humes. 1982. Identification of the aminoglycoside receptor of renal brush border membranes. J. Pharmacol. Exp. Ther. 222:350-358.

34. Bennett, W. M., C. E. Plamp, D. N. Gilbert, and G. A. Porter. 1978. Kinetics of gentamicin uptake in cortical slices and the effect of aminoglycoside pretreatment on the transport of PAH and NMN. In Nephrotoxicity: Interactions of Drugs with Membrane Systems, Mitochondria and Lysosomes. J. P. Fillastre, editor. Masson New York, 143148.

35. Kluwe, W. M., and J. B. Hook. 1978. Analysis of gentamicin uptake by rat renal cortical slices. Toxicol. Appl. Pharmacol. 45:531539.

36. Barza, M., T. Murray, and R. J. Hamburger. 1980. Uptake of gentamicin by separated viable renal tubules from rabbits. J. Infect. Dis. 141:510-517.

37. Pastoriza-Munoz, F., R. L. Bowman, and G. J. Kaloyanides. 1979. Renal tubular transport of gentamicin in the rat. Kidney Int. 16: 440-450.

38. Schacht, J. 1985. Molecular mechanisms of aminoglycoside toxicity. Assoc. Res. Otolaryngol. 8:68. (Abstr.)

39. Balogh, K., F. Hiraide, and D. Ishii. 1970. Distribution of radioactive dihydrostreptomycin in the cochlea. Ann. Otol. Rhinol. Laryngol. 79:641-652.

40. Von Ilberg, C., H. Spoendlin, and W. Arnold. 1971. Autoradiographical distribution of locally applied dihydrostreptomycin in the inner ear. Acta Otolaryngol. 71:159-165.

41. Portmann, M., J. Darrouzet, and Ch. Coste. 1974. Distribution within the cochlea of dihydrostreptomycin injected into the circulation. Arch. Otolaryngol. 100:473-475.

42. Silverblatt, F. J., and C. Kuehn. 1979. Autoradiography of gen- tamicin uptake by the rat proximal tubular cell. Kidney Int. 15:335345.

43. Just, M., and E. Habermann. 1977. The renal handling of polybasic drugs. 1. Gentamicin and aprotinin in intact animals. NaunynSchmiedebergs Arch. Pharmakol. 300:57-76.

44. Hawkins, J. 1973. Comparative otopathology: aging, noise, and ototoxic drugs. Adv. Oto-rhino-laryngol. 20:125-141.

45. Lawrence, M. 1973. Cochlear physiology and aging process. In Vascular Disorders and Hearing Defects. A. J. de Lorenzo, editor. University Park Press, Baltimore. 136-142.

46. Gilbert, D. N., D. C. Houghton, W. M. Bennett, C. E. Plamp, K. Reger, and G. A. Porter. 1979. Reversibility of gentamicin nephrotoxicity in rats: recovery during continued drug administration. Proc. Soc. Exp. Biol. Med. 160:99-103.

47. Luft, F. C., L. I. Rankin, R. S. Sloan, and M. N. Yum. 1978. Recovery from aminoglycoside nephrotoxicity with continued drug administration. Antimicrob. Agents Chemother. 14:284-287.

48. Wersäll, J., and A. Flock. 1964. Suppression and restoration of the microphonic output from the lateral line organ after local application of streptomycin. Life Sci. 3:1151-1155.

49. Thomsen, J., B. Friis, K. Jensen, K. Bak-Pedersen, and P. K. Larsen. 1979. Tobramycin ototoxicity. Repeated courses of high dosage treatment in children with cystic fibrosis. J. Antimicrob. Chemother. 5: 257-260.

50. Fee, W. E. 1980. Aminoglycoside ototoxicity in the humans. Laryngoscope. 90 (Suppl 24):1-19.

51. Lohdi, S., N. D. Weiner, and J. Schacht. 1979. Interactions of neomycin with monomolecular films of polyphosphoinositides and other lipids. Biochim. Biophys. Acta. 557:1-8.

52. Shiozawa, K., and K. Yanagisawa. 1979. Effects of neomycin on the lateral line organ of the mudpuppy. Proc. Jpn. Acad. Ser. B. Phys. Biol. Sci. 55:374-379.

53. Kroese, A. B. A., and J. Van Den Bercken. 1982. Effects of ototoxic antibiotics on sensory hair cell functioning. Hear. Res. 6:183-197.

54. Takada, A., and J. Schacht. 1982. Calcium antagonism and reversibility of gentamicin-induced loss of cochlear microphonics in the guinea pig. Hear. Res. 8:179-186.

55. Davis, R. R., R. E. Brummett, T. W. Bendrick, and D. L. Himes. 1984. Dissociation of maximum concentrations of kanamycin in plasma and perilymph from ototoxic effect. J. Antimicrob. Chemother. 14:291302.

56. Lawrence, M. 1980. Inner ear physiology. In Otolaryngology. 2nd ed. M. M. Paparella, D. A. Shumrick, editors. W.B. Saunders, Philadelphia. 1:216-240.

57. Engström, H. 1960. The cortilymph, the third lymph of the inner ear. Acta Morphol. Neerl-Scand. 3:195-204. 